\title{
Application of the multiuse encapsulator agent F-500 for environmental remediation
}

\author{
Luigi Pane, Elisabetta Giacco, Gian Luigi Mariottini \\ Department of Earth, Environment and Life Sciences, University of Genova, Italy
}

\begin{abstract}
In the framework of the Risk Assessment procedure for the ecotoxicological evaluation of compounds used in the aquatic environment, tests with target species must be carried out. This paper reports the results concerning the evaluation of the acute toxicity of F-500 micelle encapsulator (Hazard Control Technologies Inc., Fayetteville, GA, USA) on cladocerans Daphnia magna, with the purpose to verify its compatibility for the aquatic environment and its adequacy for the remediation of soils polluted with hydrocarbons. The obtained results show that by adding F-500 to diesel-polluted soils, the toxicity on Daphnia magna decreases remarkably, indicating the usefulness of this compound to fight the environmental pollution consequent to hydrocarbon dumping.
\end{abstract}

\section{Introduction}

The surfactants are synthetic organic chemicals used in industrial employments, in the formulation of detergents, household and personal care cleaning products, as well as dispersants and emulsifiers. ${ }^{1,2}$ Due to their wide use, they can be an important source of pollution needing to be carefully controlled ${ }^{3}$ because their occurrence in untreated effluents and in soils can induce remarkable toxicity to organisms. ${ }^{4-6}$

According to US Environmental Protection Agency (EPA), the micelle encapsulator F-500 (Hazard Control Technologies Inc., Fayetteville, GA, USA) is a surfactant included into the surface washing agent (SWA) category (http://www.epa.gov/oem/content/ncp/products/f500.htm) and is employed as extinguishing agent as well as dis-

Correspondence: Luigi Pane, Department of Earth, Environment and Life Sciences, University of Genova, viale Benedetto XV, 16132 Genova, Italy. Tel. +39.010 .353 .8311 - Fax: +39.010 .352 .169 .

E-mail: pane@unige.it

Key words: pollution, surfactants, F-500, ecotoxicity tests, Daphnia magna.

CCopyright L. Pane et al., 2014

Licensee PAGEPress, Italy

Journal of Biological Research 2014; 87:2131

doi:10.4081/jbr.2014.2131

This article is distributed under the terms of the Creative Commons Attribution Noncommercial License (by-nc 3.0) which permits any noncommercial use, distribution, and reproduction in any medium, provided the original author(s) and source are credited. persant to fight hydrocarbon dumping waters. ${ }^{7}$ Structure activity relationships studies showed that the active-principle of F-500 - 2Ethylhexanoic acid - has a mild toxicity against aquatic organisms. ${ }^{8}$

Considering that the risk assessment procedure for the ecotoxicological evaluation of compounds requires tests with representative and properly chosen target species, in this research the toxicity of eluates and elutriates from soils polluted with diesel and treated with F-500 was evaluated on the freshwater cladoceran Daphnia magna, a widely used organism in ecotoxicological testings, in order to verify the compatibility of F-500 for the aquatic environment and its potential usefulness for the remediation of hydrocarbon-polluted soils.

\section{Materials and Methods}

Daphnia magna (Crustacea, Cladocera) specimens have been obtained from commercial ephippia (Daphtoxokit, batch DM281009; Microtox, Milan, Italy), maintained at $20 \pm 2{ }^{\circ} \mathrm{C}$ in aerated and properly screened mineral water supplemented with $0.45 \mathrm{~mm}$-filtered 1:100 $\mathrm{CaCl}_{2}$ solution and $0.45 \mathrm{~mm}$-filtered $1: 100 \mathrm{NaHCO}_{3}$ solution, and fed with algae (Pseudokirchneriella subcapitata). Before the test, 30 females were isolated and overfed for $24 \mathrm{~h}$; the offsprings born during this period were used in the test and exposed for $24 \mathrm{~h}$, at $20 \pm 2^{\circ} \mathrm{C}$ and 16:8 light:dark period, to soil eluates and elutriates in multiwell plates with polyethilene inserts provided with $74 \mathrm{~mm}$ porosity basal membrane (Netwell $^{\mathrm{TM}}$; Corning Inc., Corning, NY, USA). Five organisms per test in quadruplicate against control test were utilized. The tested F500 concentrations were chosen considering the results of preliminary assays. The acute toxicity was evaluated estimating the percent immobilization of treated newborn specimens after $10 \mathrm{sec}$ according to the Organisation for Economic Co-operation and Development (OECD). ${ }^{9}$

The artificial soil was prepared according to standardized procedures. ${ }^{10}$ Soil constituents were previously dried and subsequently dampened with deionized water in order to obtain $40-60 \%$ of the maximum water retention. The artificial soil was treated with commercial diesel and with F-500 at the concentration (1.5\%) known to be nontoxic for the organisms, ${ }^{11}$ packed up in $5 \mathrm{~cm}$ diameter glass columns and subsequently eluted with deionized water to obtain the eluate, according to the EPA method. ${ }^{12}$ The elutriate was obtained placing soil aliquots and deionized water (1:4) in glass beakers and stirring them for 1 h. ${ }^{12,13}$ For both eluate and elutriate testings the following four samples were prepared and subsequently tested: i) control (only soil), ii) soil+diesel, iii) soil+1.5\% F-500, iv) soil+diesel+1.5\% F-500. Two different tests were carried out with the eluate using two different amounts of both compounds (test A: Diesel $10 \mathrm{~mL}, \mathrm{~F}-5005 \mathrm{~mL}$; test B: Diesel $20 \mathrm{~mL}, \mathrm{~F}-50010 \mathrm{~mL}$ ), thus maintaining unchanged the Diesel:F500 rate (2:1). Four different tests were carried out with the elutriate maintaining unchanged the diesel amount and varying the diesel:F500 rate, namely 2:1 (C), 1:1 (D), 1:2 (E), 1:4(F). 


\section{Results}

The results of tests are shown in Table 1. The data confirm that F-500 is not toxic to daphnids and clearly show that by mixing F-500 to a soil pollutant (commercial diesel) the acute toxicity induced by eluates and elutriates on cladocerans decreases remarkably. This allows to confirm the eco-compatibility of F-500 and its suitability for soil remediation.

\section{Discussion}

F-500 micelle encapsulator (Hazard Control Technologies Inc.) is a mixture of ionic and non-ionic surfactants based on fatty acid esters with aliphatic polyalcohols in watery solution used as fire fighter agent as well as dispersant against hydrocarbon pollution; it is an easy-to-use compound effective mainly under aerobic conditions, useful for the remediation of soils and able to improve the biological degradation of contaminants carried out by natural microbial populations as well as to stimulate the biodegradation reducing the toxicity of environmental pollutants or making them innocuous. F-500 allows to restore the usage of the treated areas hastening the self-regeneration of contaminated soils and restoring rapidly the ecological equilibrium (http://www.fctservices.co.uk/F-500-land-application/).

As a matter of fact, F-500 has been indicated to be able to reduce hydrocarbon concentrations within the soil environment and therefore to be active for soil remediation. ${ }^{14} \mathrm{~F}-500$ has high affinity for soil particles and it has been demonstrated that $0.1 \%$ F-500 solutions are adsorbed almost completely (>99\%) in soils; furthermore, after elution of soil with water $<1 \%$ of F-500 was found into the eluate. ${ }^{15}$ Furthermore, the overall eco-compatibility ${ }^{11,16}$ and the low toxicity against marine crustaceans and fish ${ }^{11,17,18}$ of F-500, evaluated through standardized parameters, ${ }^{19}$ are known.

\section{Conclusions}

The tests carried out in this study have shown an evident decrease of the toxicity in soils treated with diesel+F-500 in comparison with those treated with only diesel. As verified in other laboratory testings, ${ }^{20}$ this result is supposed to be due to the power of the compound to encapsulate the hydrocarbon molecules present in the soil, extracting and maintaining them in watery solution, thus reducing their toxicity and availability and consequently making them more accessible to the remediation processes. Tthe hydrocarbons could be made less available to the organisms thus resulting less toxic. Therefore, our results show a potential protective effect of F-500 against the damage exerted by pol- lution on aquatic organisms and, as recently reported, ${ }^{14}$ the suitability of this compound to counteract the hydrocarbon contamination of soil.

\section{References}

1. Nyberg H. Growth of Selenastrum capricornutum in the presence of synthetic surfactants. Water Res 1988;22:217-23.

2. Sandbacka M, Christianson I, Isomaa B. The acute toxicity of surfactants on fish cells, Daphnia magna and fish. A comparative study. Toxicol in Vitro 2000;14:61-8.

3. Seki A, Tokita K. Surfactant cytotoxicity assay based on a silicon transducer. Chemosphere 2009;76:341-4.

4. Ankley GT, Burkhard LP. Identification of surfactants as toxicants in a primary effluent. Environ Toxicol Chem 1992;11:1235-48.

5. Mori M, Kawakubo N, Wakabayashi M. Cytotoxicity of surfactants to the FHM-sp cell line. Fisheries Sci 2002;68:1124-8.

6. Liwarska-Bizukojc E. Ecotoxicity of surfactants in the terrestrial environment. Fresen Environ Bull 2009;18:1666-73.

7. HCT Service Limited. F-500: encapsulator agent dispersant application overview. F-500 within an aquatic environment. HCT New Taipei City: Service Limited ed.; 2010. Available from: http://www.fctservices.co.uk/docs/MarineNew.pdf

8. Staples CA. A review of the environmental fate and aquatic effects of a series of $\mathrm{C} 4$ and $\mathrm{C} 8$ oxo-process chemicals. Chemosphere 2001;45:339-46.

9. OECD. Guideline for testing of chemicals. Daphnia sp., acute immobilisation test and reproduction test. Guideline 202.2004 . Paris: Organisation for Economic Co-operation and Development ed.; 2004. Available from: http://www.oecd.org/dataoecd/17/21/ 1948249.pdf

10. OECD. Guidelines for testing of chemicals No. 207. Earthworm, acute toxicity test. Paris: Organisation for Economic Co-operation and Development ed.; 1984.

11. Giacco E, Mariottini GL, Pane L. [Valutazione ecotossicologica de prodotto estinguente F-500 su organismi d'acqua dolce appartenenti a diversi livelli trofici]. In: Benassi G, Giordani G, Viaroli P, eds. [XVIII Congresso della Società Italiana di Ecologia, "Ecologia, emergenza, pianificazione". Parma 1-3 settembre 2008]. [Proc. in Italian]. Parma: Società Italiana di Ecologia ed.; 2008. pp 144-145.

12. EPA. Methods for collection, storage and manipulation of sediments for chemical and toxicological analyses: technical manual. EPA-823-B-01-002. Washington, DC: Environmental Protection Agency ed.; 2001.

13. Nappi P, Jacomini C. [Guida tecnica su metodi di analisi per il suolo e i siti contaminati. Utilizzo di indicatori ecotossicologici e biologici]. [Book in Italian]. Rome: Agenzia per la protezione dell'ambiente e per i servizi tecnici ed.; 2002. Available from:

Table 1. Percent immobilization of Daphnia magna exposed to different amounts of contaminated soil eluates and elutriates.

\begin{tabular}{lccccc} 
& Test & Control & F-500 $1.5 \%$ & Diesel & Diesel+F-500 $1.5 \%$ \\
Contaminated soil eluates & A & $6.0 \pm 8.9$ & 0 & $31.8 \pm 24.4$ & $12.7 \pm 20.0$ \\
& B & 0 & $5.0 \pm 0.0$ & $46.7 \pm 17.5$ & $16.7 \pm 12.5$ \\
Contaminated soil elutriates & C & 0 & 0 & $70.0 \pm 14.1$ & $70.0 \pm \pm 14.1$ \\
& D & 0 & 0 & $70.0 \pm 7.0$ & $40.0 \pm 28.2$ \\
& E & $2.0 \pm 4.5$ & 0 & $70.0 \pm 7.0$ & $31.8 \pm 23.5$ \\
& F & $2.0 \pm 4.5$ & 0 & $16.0 \pm 14.0$ \\
\hline
\end{tabular}

Values are expressed as means \pm standard deviation. 
http://ctntes.arpa.piemonte.it/pubblicazioni/RTI_CTN_SSC_2_200 2.pdf

14. Alberta Environment and Patch H2S Services Limited. F-500: Canadian testing. Case study testing. Details of tests completed in Canada utilising F-500 in various contaminated land scenarios. Edmonton: Alberta Environment and Patch H2S Services Limited ed.; 2010. Available from: http://www.fctservices.co.uk/docs/Albertaand-Patch-tests.pdf

15. Commonwealth of Australia. National industrial chemicals notification and assessment scheme. Full public report. Chemical in F500. File no. EX/42(NA/976). Sydney: Commonwealth of Australia ed.; 2004. Available from: http://www.chemcas.org/msds113/supplier/cas/3/1777413040.asp

16. TIWET. A study of the physical properties, biological effects and possible usages of F-500 in environmental protection and restora- tion. Vapor reduction. Clemson, SC: The Institute of Wildlife and Environmental Toxicology ed.; 1997.

17. EPA. Oil program center. F-500. Technical product bulletin sw-30. Washington, DC: Environmental Protection Agency ed.; 2002. Available from: http://www.epa.gov/oem/content/ncp/products/ f500.htm

18. ARPA Ferrara. [Rapporto di prova 002971/05/FE]. [Book in Italian]. Ferrara: Agenzia Regionale Protezione Ambiente ed.; 2005.

19. GESAMP. The revised GESAMP hazard evaluation procedure. London: Joint Group of Experts on the Scientific Aspects of Marine Environmental Protection ed.; 2002.

20. Commonwealth of Australia. National industrial chemicals notification and assessment scheme. Full public report: Chemical in F500. File no: NA/976. Sydney: Commonwealth of Australia ed.; 2002. 